\title{
DE COMO A UNIVERSIDADE ENSINA MAIS DO QUE AFIRMA ENSINAR: O LIVRO O PRIMEIRO ANO - COMO SE FAZ UM ADVOGADO, DE SCOTT TUROW
}

\author{
ON HOW UNIVERSITY TEACHES MORE THAN IT CLAIMS \\ TO TEACH: THE BOOK ONE L: THE TURBULENT TRUE \\ STORY OF A FIRST YEAR AT HARVARD LAW SCHOOL, BY \\ SCOTT TUROW
}

\section{DE COMO LA UNIVERSIDAD ENSEÑA MAS DE LO QUE AFIRMA ENSEÑAR: EL LIBRO ONE L: THE TURBULENT TRUE STORY OF A FIRST YEAR IN HARVARD LAW SCHOOL, DE SCOTT TUROW}

Juliana de Souza Silva ${ }^{1}$

ORCID: https://orcid.org/0000-0002-2790-8479

\begin{abstract}
Resumo: $O$ artigo trata do livro 0 primeiro ano: como se faz um advogado publicado no Brasil em 1994. Nele, Scott Turow narra as angústias, dificuldades e triunfos vividos quando estudante do primeiro ano da graduação na Faculdade de Direito de Harvard, uma das mais bem conceituadas dos Estados Unidos. Durante seu período na instituição, Turow manteve a escrita de um diário onde relatava trechos e reflexões a respeito de suas experiências como aluno. O depoimento dramático do autor evidencia os esforços empreendidos para fazer-se advogado, o que pressupõe "aprender a pensar" e a se comportar como um. Nesse processo, os estudantes são apresentados aos conteúdos necessários à formação na área, ministrados por professores que mesmo tendo perfis docentes distintos conduziam as aulas a partir do chamado "método socrático", em que os alunos são individualmente interrogados sobre suas impressões acerca dos conteúdos. Contudo, durante o percurso acadêmico os jovens também confrontam-se com uma diversidade de saberes não-ditos advindos da tradição institucional de um "sistema de estudos que pouco mudou no último século", ofertador implícito de modos de ser, de saber fazer e de saber dizer transmitidos e incorporados de forma não sistematizada pelos estudantes, que sentiam um profundo pesar por identificarem estar "se tornando pessoas estranhamente diferentes daquelas que chegaram à faculdade". A partir da noção de inconsciente da escola cunhada por Pierre Bourdieu, este artigo propõe-se a analisar as práticas docentes e as experiências discentes relatadas por Scott Turow, buscando compreender os modos como as estruturas institucionais transmutam-se em estruturas cognitivas.
\end{abstract}

Palavras-chave: Memórias autobiográficas. Relação pedagógica no ensino superior. Práticas docentes. Inconsciente da escola.

1 Universidade Cruzeiro do Sul (UNICSUL). São Paulo - SP 
Abstract: The article is about the book One L: The Turbulent True Story of a First Year at Harvard Law School published in Brazil in 1994. In it, Scott Turow narrates the anguish, difficulties and triumphs he experienced as a first-year undergraduate student at Harvard Law School, one of the most highly regarded in the United States. During his time at the institution, Turow kept writing a diary where he reported excerpts and reflections on his experiences as a student. The dramatic testimony of the author highlights the efforts undertaken to become a lawyer, which presupposes "learning how to think" and to behave like one. In this process, students are introduced to the content which is necessary for their formation in the area, taught by professors who, despite having different teaching profiles, conducted classes using the so-called «Socratic method», in which students are individually questioned about their impressions on the content. However, during their academic career, young people are also confronted with a diversity of unspoken knowledge arising from the institutional tradition of a "system of studies that has changed little in the last century", an implicit provider of ways of being, of knowing how to do and of knowing how to say transmitted and incorporated in a non-systematized way by the students, who felt a deep regret for identifying that they were "becoming strangely different people from those who arrived at college". Based on the notion of the unconsciousness of the school coined by Pierre Bourdieu, this article aims to analyze teaching practices and student experiences reported by Scott Turow, seeking to understand the ways in which institutional structures are transmuted into cognitive structures.

Key-words: Autobiographic memories. Pedagogical relations in Higher Education. Teaching practices. Unconsciousness of the school.

Resumen: El artículo aborda el libro One L: The Turbulent True Story of a First Year in Harvard Law School publicado en Brasil, en 1994, con el título O primeiro ano: como se faz um advogado. En la obra, Scott Turow narra las angustias, dificultades y triunfos vividos cuando era estudiante del primer año de grado en la Facultad de Derecho de Harvard, una de las más reconocidas de Estados Unidos. Durante su período en la institución, Turow mantuvo la práctica de escribir un diario, donde relataba fragmentos y reflexiones sobre sus experiencias como alumno. El testimonio dramático del autor evidencia los esfuerzos emprendidos para hacerse abogado, lo que presupone «aprender a pensar» y a comportarse como uno. En ese proceso, se presentan a los alumnos los contenidos necesarios a la formación en el área, impartidos por profesores que, aunque tengan perfiles docentes distintos, conducen las clases a partir del llamado «método socrático» en que se interroga individualmente a los alumnos sobre sus impresiones acerca de los contenidos. Sin embargo, durante la trayectoria académica, los jóvenes también se enfrentan a una diversidad de saberes no dichos, provenientes de la tradición institucional de un «sistema de estudios que poco cambió en el último siglo», que ofrece implícitamente modos de ser, de saber hacer y de saber decir, transmitidos e incorporados de una manera no sistematizada por los estudiantes, que sienten una profunda angustia por identificar que están «volviéndose personas extrañamente diferentes de aquellas que llegaron a la facultad». A partir de la noción de inconsciente de la escuela de Pierre Bourdieu, este artículo se propone a analizar las prácticas docentes y las experiencias discentes relatadas por Scott Turow, buscando comprender los modos como las estructuras institucionales se transmutan en estructuras cognitivas.

Palabras clave: Memorias autobiográficas. Relación pedagógica en la enseñanza superior. Prácticas docentes. Inconsciente de la escuela.

\section{INTRODUÇÃO}

$17 / 11 / 1975$

É manhã de segunda-feira e quando entro no prédio principal posso sentir o estômago dar um nó. Pelos próximos cinco dias vou achar que sou um pouco menos inteligente que qualquer outro à minha volta. Na maior parte do tempo estarei imagi- 
nando que o privilégio que desfruto me foi conferido como uma espécie de embuste peculiar. Terei a certeza de que, não importa o que faça, não farei bastante bem; e, quando fracassar, sei que vou morrer de vergonha. Na sexta-feira estarei com os nervos em frangalhos, de insônia, pressão e fadiga intelectual, a ponto de não saber se conseguirei sobreviver ao dia. Depois de anos sem fumar, recomecei; ultimamente, pareço estar bebendo um pouco todas as noites. Não tenho tempo para ler um livro ou uma revista e me encontro tão distante das notícias do mundo que muitas vezes sinto que cai do lado escuro do planeta. Mantenho-me distraído na maioria das ocasiões e tenho dificuldade para entabular uma conversa, até mesmo com minha mulher. Às vezes, inesperadamente, posso ser dominado por sentimentos intensos de pânico, depressão, uma necessidade indefinida, e as conversas e ironias, para levantar o moral, que mantenho comigo mesmo, só parecem agravar o problema. Sou um estudante de direito no primeiro ano na faculdade, e há muitos momentos em que não passo de um caos total (TUROW, Scott. O primeiro ano como se faz um advogado, 1994, p. 9).

Recentemente, fui apresentada à obra $O$ primeiro ano - como se faz um advogado $^{2}$, de Scott Turow ${ }^{3}$, que relata sua experiência como aluno ingressante aos 26 anos na Faculdade de Direito da Universidade de Harvard, em Cambridge, Massachusetts - "a mais antiga, maior e talvez mais respeitada das faculdades de direito dos Estados Unidos" (Turow, 1994, p.11). Durante seu primeiro ano na instituição, Turow manteve a escrita de um diário em que descrevia seu cotidiano como estudante e elaborava reflexões a respeito dos modelos de excelência apresentados aos alunos, sobre as dinâmicas das aulas, os perfis docentes, a competitividade promovida pelos próprios professores e assimilada pelos alunos e, finalmente, sobre as angústias e dificuldades vividas em uma instituição tradicional, fundada em 1817, que mesmo promovendo certos desconfortos e sofrimentos aos seus estudantes - como pode ser observado no excerto que inicia este artigo - também fazia com que se sentissem felizes por integrarem-na e por superarem os desafios triunfando diante do que thes era ensinado: "Sinto-me feliz por figurar entre os herdeiros de suas tradições" (op. cit., p.13).

A partir de um depoimento, por vezes, dramático, o autor mostra os esforços feitos para fazer-se advogado, o que pressupõe "aprender a pensar", a falar e a se comportar

2 Agradeço ao Prof. Dr. Jaime Francisco P. Cordeiro, docente do Departamento de Metodologia do Ensino e Educação Comparada da Faculdade de Educação da Universidade de São Paulo, por ter me apresentado o livro de Scott Turow, que já há algum tempo é proposto por ele aos alunos da disciplina de Didática do primeiro ano do curso de Pedagogia como forma de fazê-los refletir sobre aspectos da prática docente e das experiências discentes.

3 Scott Frederick Turow nasceu em Chicago em 12 de abril de 1949 em uma família de ascendência judaica. É escritor e advogado dos Estados Unidos e já escreveu treze livros, sendo onze de ficção. Suas obras foram traduzidas para mais de 40 idiomas e venderam mais de 30 milhões de exemplares no mundo, algumas foram adaptadas para o cinema e para a televisão. Em 1977, Turow escreveu One L: The Turbulent True Story of a First Year at Harvard Law School, traduzido para o português como, O primeiro ano: como se faz um advogado, em que narra seu primeiro ano na faculdade de direito Harvard. Tornou-se Procurador Geral Adjunto em Chicago, cargo que ocupou até 1986, participando de diversas investigações criminais, principalmente em casos de corrupção. Foi presidente do Authors Guild (associação de escritores dos Estados Unidos), entre 1997 e 1998. Atualmente é sócio do escritório de advocacia Sonnenschein Nath \& Rosenthal. 
como um. Durante esse processo, os estudantes confrontavam-se com uma diversidade de saberes difusos advindos de uma tradição institucional de um "sistema de estudos que pouco mudou no último século", ofertador implícito de modos de ser, de saber fazer e de saber dizer transmitidos e incorporados de forma não sistematizada pelos estudantes, que percebiam as mudanças pelas quais estavam passando ao relatarem, com profundo pesar, estarem "se tornando pessoas estranhamente diferentes daquelas que chegaram à faculdade", como ambos os excertos abaixo demonstram:

\footnotetext{
- Eles estão me transformando em outra pessoa - disse ela, referindo-se aos professores - Estão me fazendo diferente.

Comentei que isso se chamava educação e ela me disse, com toda razão, que eu estava sendo irreverente.

- É alguém que não quero ser - acrescentou Gina - Não tem a impressão de que está sendo doutrinado durante todo o tempo?

Eu não tinha certeza se me sentia assim, mas quando Gina e eu sentamos para almoçar comecei a compreender que, para ela e muitas outras pessoas na turma, havia uma crise em andamento, que ainda não me afetara tão profundamente (op. cit., p. 69).

- Não me importa se Bertram Mann não quer saber como eu me sinto em relação à prostituição - ela disse durante o almoço naquele dia. - Eu sinto uma porção de coisas sobre a prostituição e têm tudo a ver sobre a maneira como penso sobre a prostituição. Não quero me tornar o tipo de pessoa que tenta fingir que os sentimentos não têm nada a ver com as opiniões. Não é condenável sentir coisas.

Gina não era a única pessoa a fazer comentários desse gênero. Mais ou menos nessa ocasião, de três ou quatro colegas, pessoas que eu respeitava, ouvi comentários similares, todos ressaltando que estavam sendo limitados e prejudicados pela instrução, forçados a sobrepor a razão seca à emoção, a cultivar opiniões que eram "racionais", mas que não tinham raízes na experiência, na vida que conheceram antes. Estavam sendo afastados de si mesmos (op. cit., p. 70).
}

Diante de tais apontamentos, o presente texto tem o propósito de analisar algumas práticas docentes, bem como as experiências discentes relatadas por Scott Turow a fim de compreender os modos como as estruturas institucionais, ou seja, as formas de funcionamento da área e da instituição transmutam-se em estruturas cognitivas, formando uma espécie de inconsciente escolar comum a todos aqueles que são produtos de um mesmo sistema de ensino, ou a todos os membros de uma disciplina ou área do conhecimento, que adquirem um conjunto de disposições comuns que "permite[m] compreender por meias palavras; e possibilita que muitas coisas, não necessariamente as menos importantes, sejam compreendidas sem que seja necessário falar delas" (Bourdieu, 2013, p. 227). A partir das contribuições de Pierre Bourdieu (2011, 2013a, 2013b) parte-se da compreensão segundo a qual as estruturas cognitivas são o produto do trabalho de inculcação explícita realizada, neste caso, pela universidade, e pela assimilação dos conteúdos específicos da área de formação, mas também e, sobretudo, pelo trabalho de inculcação estrutural, sem intenções 
claras nem sujeitos, que se opera por meio da imersão num ambiente estruturado como a Faculdade de Direito de Harvard.

\section{O INTERESSE PELO CURSO DE DIREITO E A ESCOLHA PELA HARVARD LAW SCHOOL}

Scott Turow era professor-assistente do departamento de inglês da Universidade de Stanford quando descobriu o interesse cada vez mais intenso pela área do Direito. Algumas coisas que andara escrevendo demandavam pesquisa legal e o trabalho com as leis the causou fascínio. Na primavera de 1974, fez o exame nacional exigido a todos os candidatos ao curso e saiu-se muito bem, acertando 749 das 800 questões propostas. Mas, mesmo assim, ele ainda relutava em abandonar a carreira estável de docente para ingressar novamente em um curso universitário. No outono seguinte, quando ficou evidente que sua nota no exame permitia a escolha entre diversas faculdades, acabou optando pela Universidade de Harvard mesmo que seus amigos formados na instituição o advertissem sobre o "lugar grande, austero e opressivo" que ela representava. Sua admiração pela reputação da instituição nutriu a crença de que as experiências desagradáveis dos amigos justificavam-se por terem ingressado na faculdade ainda muito jovens e pouco amadurecidos, diferentemente dele que já tinha uma profissão, era casado e mais velho ao optar pela carreira. De todo modo, Turow preocupava-se com a possibilidade de fazer a escolha errada ao abandonar o ensino na universidade e ingressar em Harvard, mas ao conversar com um amigo estudante de pós-graduação do departamento onde trabalhava em Stanford sobre seus receios ouviu o seguinte conselho, que o acompanhou até decidir-se de fato por cursar a Faculdade de Direito:

\footnotetext{
- Escute - ele me disse -, se eu fosse para a faculdade de direito seria por querer encontrar o inimigo. Acho que é uma boa coisa para fazer. E se quisesse encontrar meu inimigo, iria para Harvard, porque teria certeza de encontrá-lo lá. [...] Compreendi que, de certa forma, [o comentário] resumia meus sentimentos em relação à faculdade de direito: o medo, as incertezas, a esperança de desafio, triunfo, descoberta. $E$ assim pensando em relação ao que havia pela frente, tornei-me ainda mais certo de que minhas decisões eram corretas (Turow, 1994, p.19).
}

Ao ingressar em Harvard e conhecer seus primeiros colegas, Turow descobriu que quase um terço provinha da Ivy League 4 , muitos deles "filhos do privilégio e da riqueza" e que agora estavam adquirindo ainda mais vantagens por estarem naquela faculdade. Estavam ali não somente pelo que a riqueza monetária que a classe de origem possibilitava,

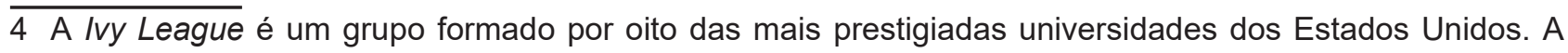
história dessas instituições está diretamente relacionada à história do país e por elas passaram vários personalidades americanas importantes, inclusive presidentes como Barack Obama, Bill Clinton e John F. Kennedy. 
mas também, por possuírem certo capital cultural herdado e incorporado e aparentemente natural e inato, que ao final da trajetória universitária Ihes proporcionaria a maior certificação de inteligência que poderiam ter: o diploma da Faculdade de Direito de Harvard, berço de grandes líderes políticos (Bourdieu, 2019). Em certa medida, esses comentários também se aplicavam a ele, que fora criado por pais prósperos, de modo que, "se as vantagens se tornassem uma base para a exclusão, ele seria um dos primeiros a sair" (Turow, 1994, p.26). E houve momentos durante aquelas primeiras semanas em que a ideia de desistir ocupou sua mente intimidada pela "genialidade e o talento dos colegas" (op. cit., p.26). Tais termos utilizados em alguns trechos da narrativa contribuem para o reconhecimento de um suposto essencialismo da inteligência de seus colegas, que desconsidera que os categorizados dessa maneira geralmente desfrutam de benesses relacionadas à classe de origem (Bourdieu, 2019). Contudo, apesar do receio por integrar a instituição, o encantamento e o orgulho por fazer parte daquele grupo seleto de estudantes também se fez presente na trajetória do autor.

\title{
O PROCESSO DE FAZER-SE UM ADVOGADO: OS PROFESSORES E TUDO AQUI- LO QUE ELES ENSINAM
}

\author{
- Pegou Perini? \\ Acenei com a cabeça, confirmando. \\ - Ouvi dizer que ele é durão. \\ - Falou tudo. Ele foi meu professor no ano passado. Não é fácil. \\ - O que ele faz....bate nos alunos? \\ - Espere para ver. - Mike sorriu, mas sacudiu a cabeça, como se alguém tivesse lhe \\ desferido um golpe. - Mas você vai sobreviver. Além do mais, há muita gente que o \\ considera um excelente professor. \\ Interroguei Mike sobre os meus outros professores. Ele não sabia muito, exceto \\ sobre Nicky Morris, o professor de Processo Civil. Ele era jovem, disse Mike, pro- \\ gressista, muito apreciado pelos alunos (Turow, 1994, p.20).
}

Quais são as relações estabelecidas entre professores e alunos no ambiente da universidade? $\mathrm{O}$ que as posturas e condutas docentes ensinam aos estudantes considerando-se que, no caso da Faculdade de Direito, tais relações circunscrevem-se em ambiente específico, o mundo profissional e universitário? Françoise Waquet (2010, p. 272) interroga-se sobre qual a natureza desse vínculo partindo da compreensão segundo a qual a relação estabelecida entre professores e alunos é assimétrica entre dominantes e dominados, mas também sugerindo que tal identificação é um tanto quanto genérica e limitante, pois ignora as formas como essas posições reconfiguram-se nos atos cotidianos dos agentes. Ignora, 
também, que as instituições de ensino representadas nas figuras de seus professores oferecem aos estudantes mais do que acreditam oferecer, pois ao determinarem um itinerário formativo mais do que apresentarem conteúdos específicos transmitem um programa de pensamento e de relação com a cultura, ao estabelecerem as maneiras como as aulas são conduzidas e como avaliam os estudantes (avaliações orais, escritas, seminários etc.) tendem a encorajar determinadas relações com a linguagem e certas posturas. Ou seja, há uma série de esquemas intelectuais, linguísticos e corporais transmitidos de modo implícito, atuando fora do alcance das tomadas de consciência crítica (Bourdieu, 2013b).

O que sabemos sobre o cotidiano das instituições de ensino superior? Azanha (1992) ao examinar a pesquisa educacional sugere que documentamos pouco a vida escolar cotidiana e tal argumento pode estender-se à vida universitária. O que as rotinas não documentadas, os hábitos e as tradições de um período podem trazer de contribuições para o entendimento do que se passa nessas instituições? As memórias de Scott Turow são prolíficas por apresentarem elementos do cotidiano no ensino superior que extrapolam a discussão sobre os conteúdos que devem ser necessariamente aprendidos pelos alunos para, neste caso, tornarem-se advogados ou sobre as metodologias adotadas pelos professores para dotá-los das competências jurídicas. Suas impressões e sensações diante da inserção na área de estudos mostram muito mais do que isso, pois enfatizam o processo de cultivo de um habitus cuja assimilação fez até com que seu corpo padecesse. Produções de cunho biográfico, como é o caso do livro em discussão neste artigo, assim como textos circunstanciais e a literatura podem ser meios potentes para o entendimento daquilo que é pouco tangível e de difícil identificação (Waquet, 2010), pois os episódios dolorosos relatados nas páginas do livro mostram um lento processo de cooptação e de iniciação que equivale, nas palavras de Pierre Bourdieu (2013, p. 110), "a um segundo nascimento". Ao contar, por exemplo, sobre os estilos docentes de seus mestres e sobre as sensações que suas aulas e posturas Ihes causavam, sobre as maneiras como um vocabulário específico foi sendo apresentado cotidianamente nas situações mais despretensiosas e sobre tantas outras experiências relatadas no decorrer da narrativa, Turow desvela uma série de aspectos e regras aprendidas arbitrariamente e que ocupam o lugar do que não é claramente dito pelos professores, mas que se apresentam nas formas como eles e os alunos estabelecem as relações e nas formas como seus "modos de ser" ensinam uma série de coisas. Tais apontamentos levam a perguntar: quais as marcas que as ações ordinárias e despretensiosas dos professores deixam nos alunos?

Françoise Waquet (2010, p. 27) percorrendo livremente o período entre o século XVII e a atualidade revela mediante a apresentação de relatos, de rituais e de práticas a profundidade de sentidos que a relação mestres e discípulos assume, traduzindo a complexidade e a diversidade de uma ligação fundada no poder, mas também nos afetos, que fazem com que os mestres sejam vividos pelos alunos das mais variadas maneiras. Em certo trecho da obra, a autora se refere a um discurso proferido em 2005 por Paolo Rossi durante a cerimô- 
nia em memória de seu mestre, Eugenio Garin. Rossi fala de Garin, mas fala, sobretudo, das relações estabelecidas entre ambos, de si mesmo e do que foi aprendido mesmo que não estivesse contido no programa. São palavras de Waquet (2010, p. 272):

\begin{abstract}
Ele começou se questionando sobre o que aprendera de Garin e sobre o que, como que fazendo um balanço, valera: "coisas" importantes, evidentemente, mas "bem menos importantes" do que os modos de fazer, "algo que tem mais relação com 'estilo' de trabalho do que com conteúdos específicos e precisos, e depois, com algo mais indeterminado e pouco tangível derivado do chamado mundo dos valores: o modo de conhecer o trabalho científico e as relações entre esse trabalho e o cotidiano.
\end{abstract}

No relato de Scott Turow (1994) somos apresentados a diversos acontecimentos envolvendo seus mestres e seus modos de ser. Aliás, boa parte de sua narrativa dedica-se a tratar dos estilos e das sensações causadas por eles nos estudantes. Antes mesmo do contato com os professores nas aulas, o dia da matrícula e o encontro ao acaso com um antigo amigo de colégio ofereceu a Turow algumas informações sobre as disciplinas que iria cursar e sobre os professores e seus estilos pedagógicos, que foram sendo aprimoradas pela própria experiência do autor durante a frequência nas aulas. Nicky Morris era um dos professores mais apreciados pelos estudantes. Tinha 31 anos (informação aludida pelo autor mais de uma vez no livro) e era "além de muito inteligente, brilhante mesmo" (op. cit., p.29). Formado na Faculdade de Direito de Harvard aos 23 anos, fora o primeiro da turma, presidente da Revista de Direito e alcançara a mais alta média como aluno nos últimos tempos. Após formado, havia trabalhado como assistente de um dos ministros do Supremo Tribunal Federal dos Estados Unidos e como advogado da União dos Trabalhadores Agrícolas, antes de começar a dar aulas em Harvard. A referência à precocidade com que Morris concluiu seus estudos e passou a ocupar a posição de docente da instituição, bem como os atributos relacionados a ele merecem especial atenção, pois as idades com que alcançou tais conquistas não são mencionadas à toa. Em seus estudos, Pierre Bourdieu (2011) identifica a existência de um cursus marcado por etapas e aquisições progressivas de conhecimentos associados a idades determinadas, sendo aqueles que se mostram competentes em idade inferior à considerada possível percebidos como precoces e com maiores chances de verem seus saberes e comportamentos associados ao dom, à genialidade e ao brilhantismo. Esse juízo acaba camuflando particularidades relacionadas à posição de classe daqueles que recebem tais qualificativos, pois tais características são atribuídas aos indivíduos como se fossem inatas, desconsiderando-se que a precocidade em demonstrar-se merecedor desses atributos ou a competência para alçar certos postos em idade inferior ao que comumente ocorre pode ter sido possível apenas pela oportunidade de acesso antecipado a privilégios que outros não tiveram. Tratando-se de uma faculdade elitizada e concorrida como é o caso de Harvard Law School, divulgar a precocidade de 
seu corpo docente tem o poder de evidenciar a adesão aos valores de "seriedade", "sendo o mais precoce nesse sentido aquele que é o mais velho entre os jovens" (Bourdieu, 2011, p. 138). Abaixo encontra-se um relato em que a jovialidade de Morris é destacada:

\begin{abstract}
"Apareceu na primeira aula com um jeans e uma camisa polo vermelha; os cabelos escuros, embora penteados, eram um pouco compridos. Encostou-se no pódio, conversando com alguns alunos, parecendo um jogador a conversar com animadoras de torcida. Morris vestia-se como os alunos e também falava em tom coloquial utilizando termos como "coisa", "esse negócio", "sabem como é" (Turow, 1994, p. 49).
\end{abstract}

Além da empatia suscitada nos alunos e advinda da forma como falava, comportava-se e se vestia Morris mostrava-se desde o início como sendo um "forasteiro" de Harvard, uma vez que criticava abertamente a faculdade de direito e a instrução jurídica de modo geral. Quanto à condução de sua aula, era heterodoxo e dizia preferir selecionar alunos para responderem às suas indagações a partir do mapa de lugares da sala, pois assim as oportunidades de falar em aula seriam iguais a todos os estudantes. Mas, caso não quisessem falar, bastava que dissessem "passo" quando chamados e complementava dizendo: "Não vou questioná-los - prometeu Morris - Não sintam que têm obrigação de apresentar desculpas. Não acredito em ter que coagi-los a dizer alguma coisa" (op. cit., 49-50). Sua postura amistosa e a permissão de que pudessem fazer qualquer tipo de pergunta fez com que os estudantes passassem a questioná-lo sobre a matéria de Contratos, pois toda a turma sentia-se intimidada demais por Perini, o responsável pela disciplina, cujo estilo docente contrapunha-se completamente ao de Morris.

Perini era temido pelos alunos, mas também era visto como um grande professor. Parecia ter passado dos cinquenta anos, tinha mais de um metro em oitenta de altura, mas era "gorducho e desajeitado" (op. cit., 38), e usava terno preto com colete apesar do calor que fazia no dia de sua primeira aula para Turow e sua turma. Neste dia, ao chegar à frente da classe, sorriu e começou a falar sobre as regras básicas a serem seguidas durante a realização do curso e logo fez algumas advertências acerca de sua disciplina e de sua postura:

- Alguns dos seus colegas podem achar que o curso de Propriedade, na primavera, é o mais difícil que eles terão. Mas vocês não vão se sentir assim, porque estarão fazendo Contratos comigo. Não sou... - ele levantou os olhos - ... uma pessoa fácil. Espero que estejam aqui todos os dias. E espero que sentem nos lugares que lhes foram designados. Nos chamados bancos dos fundos quero ver apenas as pessoas que estão nos visitando, à procura de um vislumbre momentâneo de algo mórbido. Risos outra vez em alguns lugares.

- Espero que estejam muito bem preparados, todos os dias. Quero ser absolutamente claro nesse ponto. Nunca ouvi a palavra "passo". Não sei o que significa "despreparado". De vez em quando, é claro, há problemas pessoais...todos os te- 
mos às vezes...que tornam impossível uma preparação plena. Se for esse o caso, quero que um comunicado por escrito seja entregue à minha secretária pelo menos duas horas antes da aula (op. cit., p. 39 e 40).

Além da apresentação das regras, na primeira aula Perini descreveu a extensa lista de temas a serem estudados. O adiantado da hora fez com que os alunos pensassem que estariam a salvo dos questionamentos. Mas, quando faltavam apenas seis minutos para o término da aula, o professor consultou o mapa de distribuição dos lugares e chamou um dos alunos para responder às suas indagações. As aulas eram comumente conduzidas a partir do "Método Socrático". De modo geral, para eles, a discussão socrática começa com a escolha de um aluno pelo professor que dirá a ele para "enunciar a causa", ou seja, oferecer uma versão oral das informações que se encontram em um sumário. Após a exposição, assim como Sócrates fazia com seus discípulos, o professor interrogará o aluno sobre o que acabou de dizer pressionando-o a dar respostas cada vez mais claras e objetivas. A discussão se encaminha dessa forma e vai ficando cada vez mais específica, até que o inquirido não seja mais capaz de responder. O professor pode escolher outro estudante a partir do mapa dos lugares da sala, mas o mais comum é que chame um dos que levantaram a mão. O substituto pode responder apenas à questão ou continuar a discussão da causa com o docente.

Apesar dos professores de Turow terem estilos didáticos muito diferentes, o "Método Socrático"5 era utilizado por todos eles, que o adaptavam da forma como desejavam. Mesmo diante da aflição e dos protestos dos estudantes, era a forma por excelência de dar aulas, utilizada inclusive por professores mais liberais e progressistas, como era o caso de Morris. Há aparentemente entre os docentes um consenso sobre a instrução socrática ser o melhor meio de "treinar os alunos para falar na linguagem jurídica desconhecida e serve também para acostumá-lo ao estilo compartimentado e inquisitivo de análise que é uma parte fundamental do processo de pensar como um advogado" (op. cit., p. 33). 0 movimento de pensar como um advogado pressupunha também saber manejar o léxico da área, apropriando-se de modos de expressão atinentes ao campo do direito. Turow já nas primeiras semanas de aula percebeu algumas modificações nos comportamentos de seus colegas de turma e constatava com admiração que pareciam excepcionalmente articulados injetando nas conversas cotidianas e despretensiosas o novo vocabulário aprendido, como se estivesse: "falando Legal entre si" (op.cit., p. 51). Ouvia-se pelos corredores "Quaere se essa posição pode ser apoiada?" ou “Deixe-me acrescentar um caveat" para indicar "Deixe-

\footnotetext{
$5 \mathrm{O}$ autor nos deixa dúvidas sobre o método socrático ter sido escolhido pelos docentes como a forma por excelência de organização das aulas por ser considerado o melhor pelos docentes de Harvard. Em certa passagem da narrativa, ele afirma ter escutado de um professor em conversa com os estudantes que uma das grandes contribuições do diretor Langdell ao ensino jurídico havia sido torná-lo barato. Instituindo o método socrático, ele encontrou uma maneira de instruir 140 pessoas ao mesmo tempo, uma forma de produção educacional em massa. Provou para os reitores de universidades de toda a América que podiam ganhar dinheiro com a abertura de uma faculdade de direito, contratando apenas uns poucos professores (op. cit., p. 100).
} 
-me dar um aviso". As pessoas ficavam nitidamente satisfeitas ao experimentarem seu "Legal" e praticavam-no umas com as outras demonstrando o gosto por se sentirem "teatrais e empoladas" ao saberem conduzir um diálogo fazendo uso de tal linguagem. Certa vez, em tom jocoso, o professor Morris resumiu o que se passava com os estudantes:

Foi Nicky Morris quem melhor resumiu o que todos nós tentávamos fazer ao usar os legalismos. Na última aula de Processo Civil naquela semana, uma mulher respondeu da seguinte maneira a uma pergunta formulada por Morris:

- O tribunal não precisa submeter matéria de jurisdição sobre a pessoa.

- Não sei se entendo o que significa - comentou Morris -, mas ainda assim estou contente por ouvi-la falar dessa maneira. Afinal, não se pode ser um pato sem aprender a grasnar (op. cit., p. 51).

Em seus estudos sobre as trocas linguísticas, Pierre Bourdieu (1996) sugere que a prática linguística comunica, além do que é explicitamente declarado, uma informação sobre certa maneira de comunicar-se pertencente a um grupo e a um estilo, que aproxima determinados grupos mediante a criação da ideia de identidade, parentesco e pertencimento. A linguagem é sempre arquitetada por valores e crenças e materializa um universo de virtudes a serem valorizadas, procuradas e hierarquizadas nos indivíduos, pois as maneiras como representamos o mundo por meio dela estão condicionadas à posição que ocupamos no espaço social. Ou seja, o nosso espaço de possíveis léxicos é construído e reconstruído socialmente e é construtor e reconstrutor de sentidos simbólicos. Ao falarmos revelamos, assim, nossa adesão a certas posições, opiniões e identidades (Bourdieu, 1996). Tais apontamentos elucidam o que levava os estudantes a adotarem certa forma de comunicação. Saber compreender e manejar aquele léxico representava muito mais do que ter competência para compreender e transitar pelos saberes específicos das disciplinas, significava mostrar-se apto a ocupar aquele espaço e ser merecedor de tudo o que ele podia lhes oferecer, significava comungar certa "essência", de modo que, os esforços para adotar essa forma de falar faziam-se nas situações de interação extraclasse entre os estudantes, nas conversas experimentais enquanto praticavam uns com os outros, pois tornarem-se advogados significava também inscrever em seus corpos certo senso prático, certas disposições permanentes incorporadas e externalizadas nas formas de se portar, de falar, de andar e, dessa maneira, de sentir e de pensar (Bourdieu, 2013b).

Com o decorrer do tempo, os professores foram se tornando seres conhecidos e deixaram de ser vistos como divindades pelos alunos. Perini continuava sendo brilhante em aula, demonstrava muita habilidade para apresentar noções difíceis aos estudantes, esquadrinhava suas mentes e era considerado por Turow seu melhor professor. Parecia somente se sentir à vontade quando estava dando aula, parecia ter uma personalidade de showman. Contudo, criava um clima de mal-estar terrível na turma e parecia satisfazer-se com isso, como mostra o relato de um colega da turma do autor: 
- Segunda, terça e quarta, as manhãs em que temos Contratos, pego o ônibus em Watertown e sinto um enjoo no estômago - confessou-me Stephen pelo telefone, na semana passada - Não dá para acreditar, mas penso na aula e me sinto mal. E quando saio da aula na quarta-feira, experimento a sensação de que a semana já acabou (Turow, 1994, p. 85).

Quanto a Morris, a convivência passou a despertar em Turow a sensação de que sua postura não era amistosa como imaginou no princípio, mas sim condescendente com os alunos. Às vezes, ao explicar certos temas, parecia deliberadamente confuso. Quando a turma não entendia, ele falava com um tom de voz mais familiar que sugeria não apenas que eram pessoas muito menos instruídas, mas também, consideravelmente menos inteligentes. Ocorreu ao autor "o pensamento de que Nicky, o famoso jogador de futebol americano, tornou-se professor em busca de um campo em que pudesse vencer sempre" (op. cit., p. 85).

\title{
O PROCESSO DE FAZER-SE UM ADVOGADO: APROPRIANDO-SE DA ÁREA
}

\begin{abstract}
Quando eu era garoto, assisti a um filme na televisão sobre um soldado americano que mantém a sanidade mental numa prisão coreana projetando uma casa em sua cabeça. Aprender um curso de direito é um processo bastante parecido: erigir os alicerces, as paredes, o telhado; norma/política/teoria; tentar lembrar exatamente como cada uma das partes se junta e se ajusta. Alguns estudantes preferem delinear cada curso pessoalmente, achando que é a melhor maneira de captar o fluxo e organização do material. Outros gostam de ler e memorizar resumos preparados. Uma terceira escola apregoa que se pode aumentar a noção do curso fazendo exames anteriores. Já experimentei um pouco de cada método e nunca pude encontrar muitas diferenças entre eles. É sempre o mesmo acúmulo lento de conhecimento, o trabalho metódico e sistemático de montar a casa, prego a prego. E quando se chega à instalação do telhado, quando o curso começa de fato a fazer sentido, com os mistérios a longo prazo se dissolvendo e os padrões básicos se tornando cada vez mais evidentes, o estudo pode parecer tão gratificante quanto era tedioso na fase de armazenamento das normas (op. cit., p. 140).
\end{abstract}

Scott Turow recorre a uma metáfora para explicar os métodos utilizados por ele e por seus colegas para conseguirem minimamente transitar no interior da área de conhecimentos escolhida. As estratégias encontradas por cada um de seus companheiros de turma eram diversas, mas todas, independentemente de como se ordenavam, tinham um propósito final: fazê-los dotados de certas habilidades para poderem lidar mais tranquilamente com as matérias que integravam o curso de Direito. Todos de diferentes maneiras buscavam aprender a pensar juridicamente. Carlos Eduardo Guimarães (1982, p. 37) parte da compreensão segundo a qual aprender é basicamente adequar-se à natureza de uma matéria dotada de lógicas, na qual os dados estão organizados de determinada forma e em que se estruturam as explicações de modos característicos. Segundo o autor, Descartes postulava: “(...) não nos tornaremos matemáticos, mesmo que decoremos todas as demonstrações, se 
o nosso espírito não for capaz, por si, de resolver qualquer espécie de problema". Aprender, de acordo com tal entendimento, pressupõe disciplinar-se a fim de pensar o mundo a partir das estruturas da matéria, ou seja, de acordo com esse entendimento, "disciplinar-se é libertar-se". E era essa liberdade que os estudantes almejavam.

No excerto que inicia essa parte do artigo sobre a trajetória de Turow em Harvard encontram-se termos que denotam a busca dos estudantes pela construção dessa disciplina/liberdade, cujos "alicerces", as "paredes" e o "telhado" representavam os movimentos feitos em busca de se fazerem livres no interior daquela área de conhecimentos e daquela instituição. Os alunos sabiam que tal iniciativa poderia Ihes trazer como resultado experienciar Harvard Law School com maior tranquilidade e esforçavam-se por se aculturar. Por mais que todo o percurso de formação seja um processo de aculturação, certamente foi no primeiro ano que os impactos relativos ao cultivo de um habitus adequado aos valores institucionais foram sentidos com maior força, quando tudo ainda era visto pelos alunos com profundo estranhamento, gerando sofrimentos mesmo em Turow, que se considerava mais maduro que seus colegas de turma por já ter passado por formações universitárias. Em certa ocasião, quando considerava estar perdendo o controle, o autor foi em busca de um psiquiatra. Ao ler sobre a extensa literatura psicológica em relação à Faculdade de Direito descobriu que sua crise não era excepcional e que alunos à beira de um ataque de nervos parecia ser mais uma das tradições da instituição. Um psiquiatra descreveu o caso da seguinte forma: "Nunca vi ansiedades mais manifestas num grupo de pessoas em circunstâncias 'normais' do que é visível nos estudantes do primeiro ano de direito" (Turow, 1994, p. 125). No decorrer do ano, Turow pôde constatar que muitos primeiranistas haviam entrado em crise de forma muito mais intensa do que a dele:

Sei de pelo menos uma tentativa de suicídio na minha turma e houve muitas pessoas que confidenciaram que haviam sido levadas a passar pela porta de um psiquiatra pela primeira vez em suas vidas, em decorrência das experiências no primeiro ano da Faculdade de Direito de Harvard. O fato de que existe um psiquiatra disponível na faculdade é bastante indicativo (op. cit., 125).

Os indicativos de que essa forma de viver a instituição fazia parte de sua tradição são dados pelo próprio autor, que registra no discurso público de Nicky Morris a menção ao fato de Harvard Law School ser uma instituição que promovia tantas dificuldades cotidianas aos seus estudantes que fazia com que se sentissem mais oprimidos por ela do que pelo tribunal ou pela guerra. As palavras proferidas por Morris para uma multidão de estudantes ao final do ano letivo são dignas de nota:

- Estou sempre encontrando graduandos da Faculdade de Direito de Harvard, pessoas de todas as idades, que me dizem que "o tribunal não mete medo". Muitos são homens que lutaram na Segunda Guerra Mundial, Coréia e Vietnã e a maioria diz que, mesmo com tais experiências, nunca se sentiu tão assustada ou oprimida 
quanto nos tempos de estudante de direito em Harvard; e que depois, em comparação, a ansiedade em entrar num tribunal pela primeira vez não foi nada (op. cit., p. 125).

Contudo, o próprio Morris assinala certa discordância em relação a essa "tradição" da instituição ao dizer:

\begin{abstract}
"Sinto-me satisfeito se podemos preparar nossos alunos para se sentirem tão confiantes no desempenho de seus deveres profissionais. Mas não me enche de orguIho ser parte de uma instituição que proporcionou a tantas pessoas os piores momentos de suas vidas. Não creio que seja uma coisa positiva dizer isso a respeito dessa faculdade. Acho que deve haver alguma coisa errada num lugar assim." (op. cit., p. 125).
\end{abstract}

A aparente discordância do professor em relação a algumas práticas empreendidas na Faculdade de Direito de Harvard não fica evidente nas referências feitas por Turow a outros docentes da instituição. As diversas reivindicações dos alunos, as notas psiquiátricas sobre seus sofrimentos e os casos de suicídio a que Turow faz menção no relato não pareceram resultar em mudanças profundas em relação à dinâmica da universidade, pelo menos no período em que o autor estudou na instituição,

\title{
O PROCESSO DE FAZER-SE UM ADVOGADO: AS PROVAS E OS EXAMES NA HARVARD LAW SCHOOL
}

Durante todo o tempo, os alunos do segundo e do terceiro anos haviam me dito que eu nunca passara por qualquer coisa parecida com um exame de direito e estavam certos. Mas isso não contribuía em nada para aumentar meu respeito pelos testes. Sentia-me insultado por eles - não há outra maneira melhor de descrever minha sensação. Eram encarados com uma seriedade institucional que levara meus colegas e eu a acreditarmos por meses que ofereceriam alguma avaliação refinada, não apenas do quanto aprendêramos, mas também - quase misticamente - das profundezas de nossa capacidade e vocação para o direito. Os exames constituíam um indicador, um campo de provas de todo o trabalho árduo e devotado. Em vez disso, não haviam passado de competições intelectuais, exercícios frenéticos que pareciam não atribuir qualquer valor à percepção e imaginação - qualidades que eu mais admirava nos outros e das quais me sentia orgulhoso quando ocorriam em mim mesmo (op. cit., p. 145).

$\mathrm{Na}$ elaboração deste artigo foram se evidenciando algumas características da Faculdade de Direito de Harvard. Ao tratarmos das expectativas dos alunos ao ingressarem na instituição e de seus estranhamentos em relação às aulas, as maneiras como os docentes apresentavam-se aos estudantes e as sensações que causavam neles buscou-se demonstrar o longo e árduo processo de fazer-se um advogado, ressaltando-se muito mais 
as condutas e aquilo que está na ordem do não explicitado do que daquilo que diz respeito aos conhecimentos necessários para se tornar um. Prosseguindo tal empreendimento, esta parte do texto dedica-se a refletir acerca das maneiras como os alunos eram avaliados na instituição. No livro em tela, Turow dedica dois capítulos para tratar das provas na Faculdade de Direito de Harvard ${ }^{6}$, talvez, pois, assim como afirma Cordeiro (2008, p. 145): "De tudo o que acontece na escola, no ensino e na aprendizagem, aquilo que parece ser mais imediatamente lembrado são os mecanismos e consequências da avaliação". As memórias dos estudantes são quase sempre muito marcadas pelas lembranças das provas e dos exames pelos quais passaram em sua vida escolar e universitária. Não raro, eles recordam-se das avaliações como sendo momentos muito sérios, em que certa postura corporal e mental diferente das aulas cotidianas era adotada (op. cit.,145). Em certos casos, essa mudança acompanha também a forma de vestir-se para o ato. Ao passar por uma avaliação que pressupunha a defesa oral de uma causa e encontrar-se com seus "oponentes", Turow dá especial atenção para a forma como estavam vestidos:

\begin{abstract}
A defesa oral foi um desastre.
No momento em que nos aproximamos da sala no Pound em que seria realizada a sessão, compreendi que Willie e eu estávamos em dificuldades. Nossos oponentes, Jim DeMarco e Jody May, apareceram em seus melhores trajes, um terno com colete e um elegante costume. Willie e eu usávamos nossos velhos paletós esportes (Turow, 1994, p. 114).
\end{abstract}

A defesa oral, processo de argumentar em voz alta perante um tribunal, é um dos elementos mais respeitados do ofício de um advogado e alguns dos exames aos quais os alunos eram submetidos imitavam a ocorrência de um júri. Para ser um advogado de alto nível, diz-se que duas coisas são necessárias:

\footnotetext{
Primeiro, deve-se ter uma eloquência extraordinária e pensamento muito ágil. O juiz pode interromper com perguntas sobre qualquer aspecto da causa, por mais trivial que seja, que lhe pareça ser um obstáculo para aceitar sua argumentação ou descartar a do oponente. Você precisa estar preparado para se manifestar sobre qualquer ponto. Para isso, uma segunda coisa é necessária: você deve conhecer o processo a fundo, até os menores detalhes (op. cit., p. 115).
}

O excerto que inicia essa parte do artigo nos dá algumas pistas sobre a maneira como Turow sentiu-se após passar pelas avaliações na instituição. O autor parece ter se dado conta de que os exames feitos serviram muito mais ao fim de instigar a competição e estabelecer hierarquias entre os alunos atestando a ignorância de alguns e a excelência de outros. A avaliação na Faculdade de Direito de Harvard tinha uma função extremamen-

6 Os capítulos intitulam-se: Dezembro e Janeiro - Provas (Primeiro Ato) e Abril e Maio - Provas (Último Ato). 
te importante para a manutenção das percepções sobre a tradição que envolvia aquele ambiente: classificar os estudantes a partir de conceitos criados mediante uma norma de excelência e, aparentemente, manter a competição entre eles, que se viam diminuídos ou sentiam-se orgulhosos e distintos diante de suas notas. Em seus estudos sobre avaliação, Philippe Perrenoud (1999) afirma que as formas ou normas de excelência apresentam-se de modos bem diversos, tendo em comum mais informar sobre a posição de dado aluno em um grupo ou sua distância em relação à norma de excelência estabelecida do que sobre a apropriação dos conteúdos e a competências dos estudantes em relação aos conhecimentos que lhes foram ensinados. Turow e a maioria de seus colegas de turma pareciam partiIhar a sensação de decepção em relação às provas realizadas. Os estudantes mal podiam acreditar que os instrumentos peculiares e limitados utilizados pelos professores seriam o critério exclusivo de classificação. A consternação em relação aos exames foi observada com frequência entre os alunos, que clamavam por uma reforma na maneira de avalia-los reivindicando trabalhos ou exames que os deixassem menos tensos. Mas, as propostas feitas eram sempre recusadas, pois, "os professores são pessoas que se saíram muito bem nos exames; na verdade, devem sua atual posição, em grande parte, a esse sucesso. É difícil não considerá-los como simplesmente perpetuando o regime em que baseiam seu senso de autoridade e amor-próprio" (Turow, 1994, p.146). Ou seja, os que se saíram bem nos exames e foram aprovados nas avaliações tendem a defender as estratégias e os esquemas de percepção, de apreciação e de ação adquiridos e aplicados. Assim, nas palavras de Pierre Bourdieu (2014c, p. 237), "[...] os melhores classificados tornam-se os melhores classificadores daqueles que entram no circuito".

As estratégias de que um professor lança mão para avaliar seus alunos põem em destaque os princípios que guiam a ação docente. No caso de Harvard, as cobranças pareciam relacionar-se muito mais à aprendizagem reprodutiva, pois se solicitava dos estudantes em muito maior medida conhecimentos baseados na memorização de informações sobre a área do direito. A decepção de Turow com a forma como seus exames organizavam-se se relacionava ao fato de que as provas feitas não consideravam a exposição de pontos de vistas e a produção de textos argumentativos, ou seja, não eram instrumentos que estimulassem a reflexão e a criação. De todo modo, apesar de muitos estudantes questionarem as formas como eram avaliados na instituição e desqualificarem as provas e exames pelos quais haviam sido submetidos, a atribuição de conceitos maiores que B causava-Ihes satisfação. Mesmo Turow, que durante seu relato questionou os exames da instituição atribuindo fortes críticas às estratégias de seus docentes para avaliarem os alunos, ao final do período demonstrou contentamento com alguns conceitos atribuídos ao seu desempenho, que o colocavam no "quarto superior da turma". Ou seja, a vontade de pertencer ao grupo dos melhor avaliados se fazia presente mesmo que o autor percebesse a inadequação e a insuficiência das avaliações: 
As notas saíram no meio do mês. Apesar da calma e distância do verão, a reação costumeira aflorou no instante em que vi o envelope. Os dedos tremeram e experimentei novamente aquela sensação de insegurança e ambivalência. Por favor, pedi, nada de Cs, mesmo enquanto acalentava a esperança de algo excepcional. As notas eram as mesmas do primeiro período, metade As, metade Bs. Ganhei um A no curso de Política, um B-mais em Propriedade; um A-menos de Nicky, um B de Perini. Boas notas, eu sabia; provavelmente me incluem em algum lugar no quarto superior da turma. Sentia-me afortunado. E ainda me encontrava pressionado por um desejo de mais (Turow, 1994, p. 219).

Findo o ano letivo, Turow, um dos "sobreviventes" do primeiro ano na Faculdade de Direito de Harvard, depara-se com as mudanças ocasionadas em si mesmo e em seus colegas durante aquele árduo processo ora "sublime", ora "terrível" de incorporação intensa de um novo modo de ser e de entender o mundo. No outono de 1976, a Harvard Law School reabriria suas portas para uma nova turma de primeiro ano, que a partir do momento de ingresso na instituição lidaria com uma nova linguagem e com os enigmas lançados pelos professores assim como fora com Turow. Os novos estudantes iriam exibir suas glórias acadêmicas, suas medalhas militares e estariam ávidos pelo Direito levando consigo a ambição, a inteligência, o charme e também seus "inimigos desconhecidos". Viveriam intensamente aquilo que Turow e sua turma haviam vivido sem que a faculdade fizesse qualquer coisa para "protegê-los de si mesmos". Afinal, há muito tempo, esse era o processo pelo qual os estudantes deveriam passar para "fazerem-se advogados".

\section{CONSIDERAÇÕES FINAIS}

O primeiro ano - como se faz um advogado foi um livro marcante para mim. Ao escrever sobre o início de sua formação em Direito na Universidade de Harvard, Scott Turow nos fornece inumeráveis elementos para a reflexão sobre as dinâmicas que envolvem a formação dos indivíduos para as quais nem sempre se dá a devida atenção. Mediante sua experiência pessoal na instituição, o autor oportuniza que conheçamos aspectos da realidade social, histórica e psicológica presentes em uma faculdade tradicional, que ocupa o lugar de uma referência formativa. A narrativa de Turow nos mostra as formas como os alunos viveram a instituição naquele ano letivo e como viveram seus mestres, que - porta vozes de uma instituição tradicional - ensinaram aos seus estudantes não apenas os conhecimentos relativos à área, mas diversos outros que não são planificados, tampouco explicitados, mas são fundamentais para a constituição do ethos e da mentalidade dos advogados. Obras desse tipo são fecundas, pois possibilitam ricas e diversas contribuições acerca das minúcias que envolvem a dinâmica universitária, visto que por meio de relatos como esse conseguimos perceber uma série de práticas que acompanham os fazeres ordinários dos professores, mas que nem sempre são percebidas.

Quando Scott Turow trata de suas experiências em Harvard faz muito mais do que compartilhar sua trajetória pessoal como aluno, lança luz a diversos problemas, conflitos, 
formas de organização, relações entre professores e alunos e tantos outros aspectos que aparentemente estendem-se a todos os que vivem sua formação naquele espaço por ser fruto de uma "tradição" educativa. De modo que, os estilos adotados pelos professores, as interações entre eles e seus estudantes, as maneiras como os exames organizavam-se e tudo o que envolvia a instituição e as relações estabelecidas em seu interior não podem de modo algum ancorar-se na ideia de que tais práticas e condutas são fruto de escolhas individuais, pois os professores e as formas como concebem o ato de ensinar vinculam-se a uma história institucional que foi se fazendo corpo em suas atitudes. Ou seja, a instituição manifesta-se nos modos como os docentes agem.

O presente texto buscou evidenciar alguns desses saberes não planificados que ocupam o lugar daquilo que não é claramente dito pelos professores, mas têm fundamental importância no processo formativo dos alunos. Acredita-se que tratar dessas minúcias é compreender melhor como o ensino se faz em qualquer uma das etapas em que ele ocorre. A escrita deste artigo se norteou por tais compreensões e de modo a finalizar as reflexões aqui realizadas, retomo a citação que António Nóvoa (2002) faz de Antoine Prost (1992) no texto que compõe este dossiê:

A primeira característica chocante no funcionamento actual das escolas é o seu caráter cego. As outras instituições interrogam-se periodicamente sobre elas próprias, reflectindo colectivamente em instâncias qualificadas sobre o seu funcionamento. Essa prática é desconhecida nos estabelecimentos de ensino. E estamos de tal modo habituados a este funcionamento às cegas, que nem sequer damos por ele. 


\section{REFERÊNCIAS BIBLIOGRÁFICAS}

AZANHA, José Mário Pires. Uma ideia de pesquisa educacional. São Paulo: EDUSP, 1992.

BOURDIEU, Pierre. A economia das trocas linguísticas: o que falar quer dizer? 2a ed. São Paulo: EDUSP, 1996.

. Homo Academicus. Florianópolis: Ed. da UFSC, 2011.

O inconsciente da escola. Pro-Posições; v. 24, n. 3 (72); p. 227-233; set./dez. 2013a.

O senso prático. $3^{a}$ Ed. Rio de Janeiro: Vozes, 2013b.

. O racismo da inteligência. In:

Questões de sociologia. Rio de Janeiro:

Vozes, 2019, p. 248-251.

CORDEIRO, Jaime F. P. Didática. $1^{\text {a }}$ Ed., $2^{\mathrm{a}}$ reimpressão, São Paulo: Contexto, 2008.

GUIMARÃES, Carlos Eduardo. A disciplina no processo ensino-aprendizagem. Didática. São Paulo, 18: 33-39, 1982.

PERRENOUD, Philippe. Avaliação - da excelência à regulação das aprendizagens. Porto Alegre: Artmed, 1999.

TUROW, Scott. O primeiro ano - como se faz um advogado. 4ª Ed. Rio de Janeiro: Record, 1994.

WAQUET, Françoise. Os filhos de Sócrates - filiação intelectual e transmissão do saber do século XVII ao XXI. Rio de Janeiro: Difel, 2010. 